\title{
ANALYSIS OF SELECTED TECHNICAL AND ECONOMIC PARAMETERS OF THE REAL ESTATE MARKET
}

\author{
Eduard Hromada ${ }^{* 1}$ \\ ${ }^{1}$ Faculty of Civil Engineering, CTU in Prague, Thákurova 7, 16629 Prague 6, Czech Republic, \\ eduard.hromada@fsv.cvut.cz, +4-202-435-3720, https://orcid.org/0000-0002-8336-8710
}

\begin{abstract}
The article describes the current situation on the real estate market in terms of these four parameters: the apartments offered for sale and rent in terms of ownership, the apartments offered for sale and rent in terms of the size of the apartment, the apartments offered for sale and rent in terms of the building material and the apartments offered for sale and rent in terms of the location. Results were obtained using EVAL software. This software continuously collects, analyses and evaluates advertised offers of real estate in the Czech Republic in a monthly period.
\end{abstract}

\section{Keywords}

Real estate market, software EVAL, statistics, market price

\section{JEL Classification}

E31 Price Level, Inflation, Deflation

R31 Housing Supply and Markets

DOI: https://doi.org/10.14311/bit.2020.03.08

Editorial information: journal Business \& IT, ISSN 2570-7434, CreativeCommons license @c) (1) published by CTU in Prague, 2020, http://bit.fsv.cvut.cz/ 


\section{Introduction}

The article analyses selected technical and economic parameters that affect the development of the real estate market in the Czech Republic. Data for the period January 2018 to June 2021 are included in the analysis. The aim of the article is to provide objective and unbiased information about current trends in the real estate market. EVAL software serves as input data for figure creation.

\section{Results}

\section{The apartments offered for sale and rent in terms of ownership}

Figure 1 shows the structure of apartments offered for sale and rent in terms of ownership. In the Czech Republic, it significantly exceeds the personal ownership of flats. There is a difference here if the apartment is offered for sale or the apartment is offered for rent. In the case of renting flats, the share of cooperative ownership is lower. In this case, there is no standard rental of the apartment, but only the conclusion of a sublease agreement, where there is a lower degree of protection of the subtenant.

When selling an apartment in cooperative ownership, there is no real property owner change. The owner of the property still remains a housing cooperative. In this case, only the lease agreement is rewritten from the original member of the cooperative to the new member of the cooperative. There is also no change in the real estate cadastre.
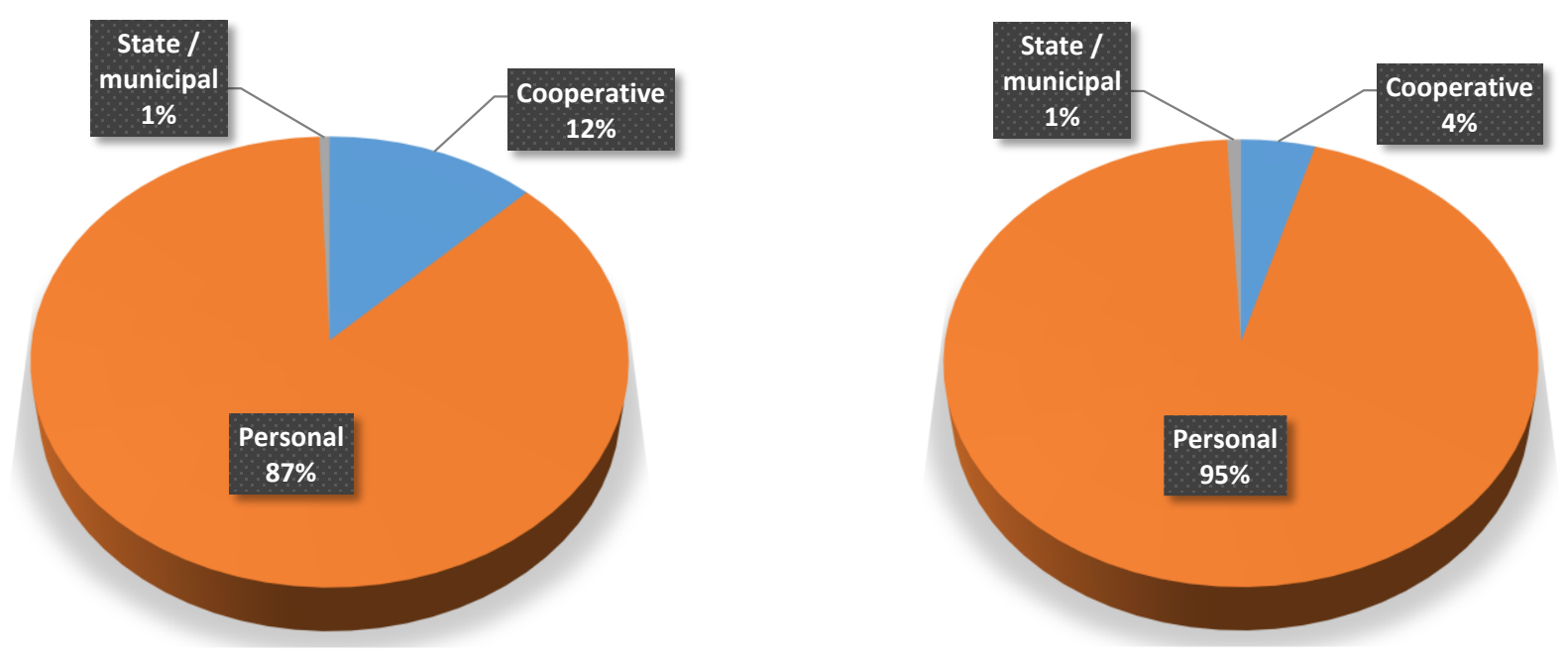

Figure 1: The structure of apartments offered for sale (left graph) and rent (right graph) in terms of ownership, January 2018 to June 2021

Source: Software EVAL

\section{The apartments offered for sale and rent in terms of the size of the apartment}

Figure 2 and Figure 3 show the structure of apartments offered for sale and rent in terms of the size of the apartment. The most represented categories of flats are $2+1,2+k k, 3+1$ and $3+k k$. These static values are caused by the nature of the housing stock in the Czech Republic and the massive construction of apartments during the socialist era.

It is possible to identify the difference in the ratio of apartments offered for sale and rent. Apartments with categories $2+1,2+k k, 3+1$ and $3+k k$ are most offered for sale. However, the most offered categories of apartment for rent are $1+1,1+k k, 2+1$ and $2+k k$. Apartments with a larger floor 
area are offered for rent significantly less than in the case of the sale of apartments. This is caused by the fact that large apartments are often offered for rent individually in separate rooms. Therefore, they do not appear in real estate advertising as whole apartments for rent. Room rental is often used by young working people and students who do not yet have a family. However, in the case of starting a family, the concept of living in a separate room in a large apartment with a shared kitchen, bathroom and toilet is unsuitable.

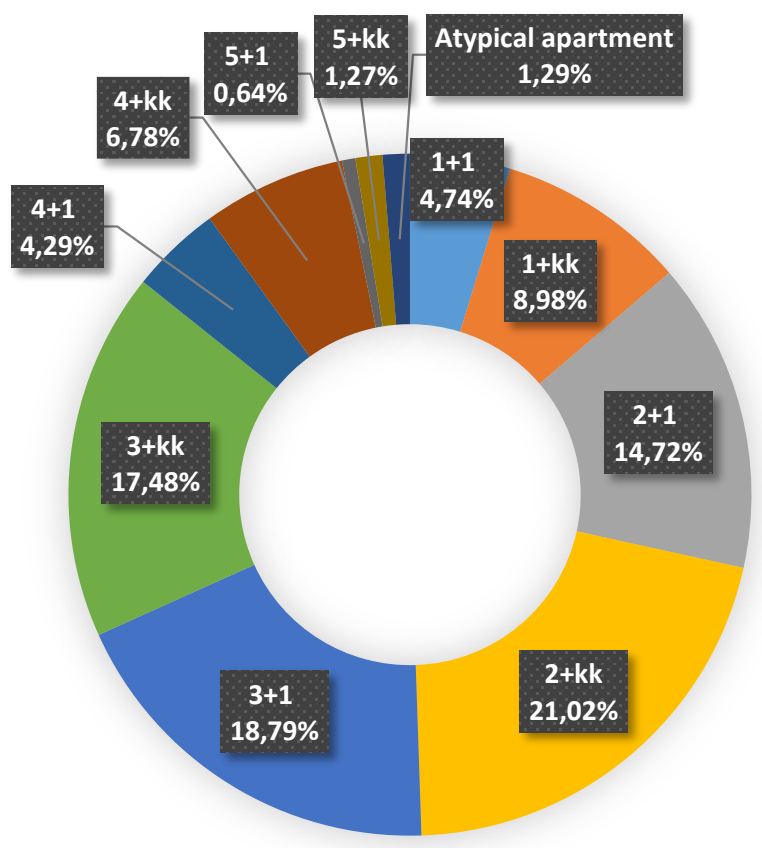

Figure 2: The structure of apartments offered for sale in terms of the size of the apartment, January 2018 to June 2021

Source: Software EVAL

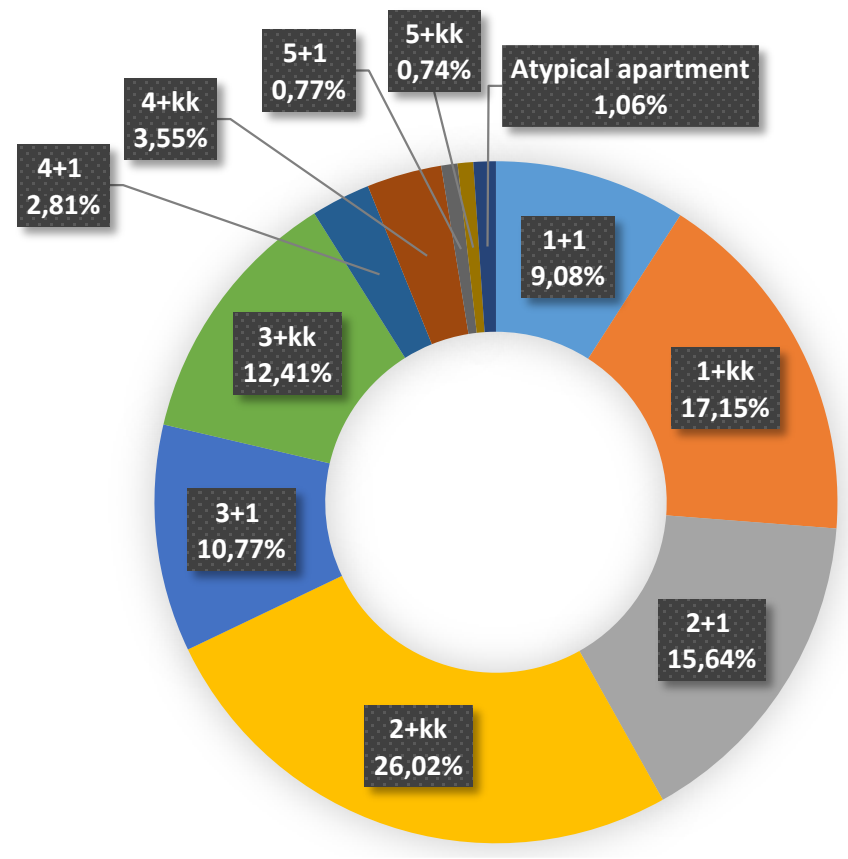

Figure 3: The structure of apartments offered for rent in terms of the size of the apartment, January 2018 to June 2021

Source: Software EVAL 


\section{The apartments offered for sale and rent in terms of the building material}

Figure 4 and Figure 5 show the structure of apartments offered for sale and rent in terms of the building material. The largest representation of apartments offered for sale and rent is in brick buildings followed by panel buildings. This is due to the structure of the housing stock in the Czech Republic which has historical roots in brick construction. It was found that fewer apartments are offered for rent in prefabricated buildings than apartments offered for sale in prefabricated buildings. This is caused by the fact that apartments in prefabricated houses are less used for investments and rent. Wooden buildings represent a completely marginal role on the real estate market in the Czech Republic.

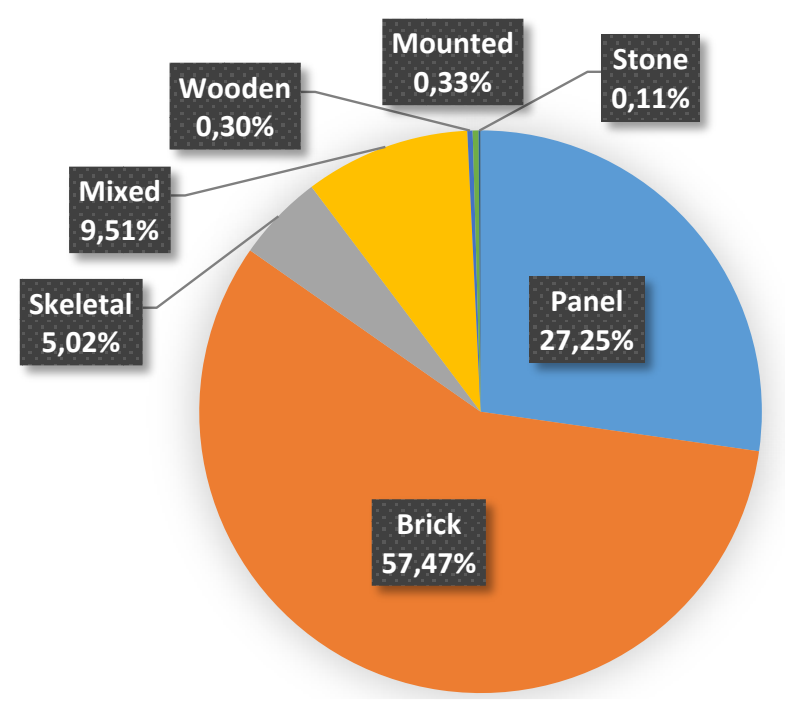

Figure 4: The structure of apartments offered for sale in terms of the building material, January 2018 to June 2021

Source: Software EVAL

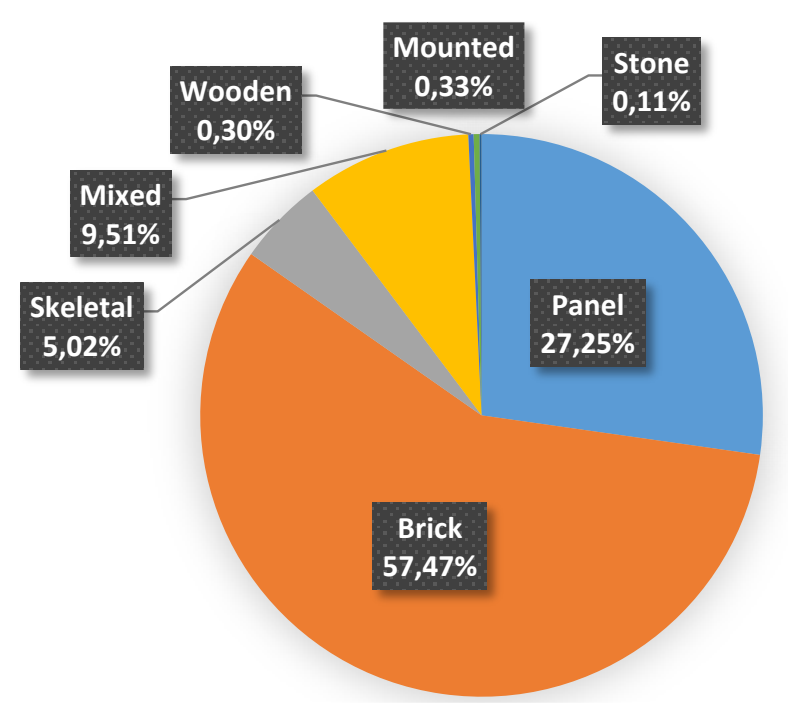

Figure 5: The structure of apartments offered for rent in terms of the building material, January 2018 to June 2021

Source: Software EVAL 


\section{The apartments offered for sale and rent in terms of the location}

Figure 6 and Figure 7 show the structure of apartments offered for sale and rent in terms of the location. A total of seven categories of apartment location are examined: housing estate, village centre, quiet part of the village, outskirts of the village, busy part of the village, semi-solitude and solitude.

It was found that the largest representation of the apartment offered for sale is in the following three categories: housing estate, village centre and quiet part of the village. In the case of renting flats, it turns out that fewer flats are offered in housing estates than in the case of the sale of flats.

It can be assumed that in both cases (sale and lease) there is some distortion, because advertisers try to present the offered property in better conditions than in reality (for example, a property located with poor access to public transport can be marked as a quiet part of the village).

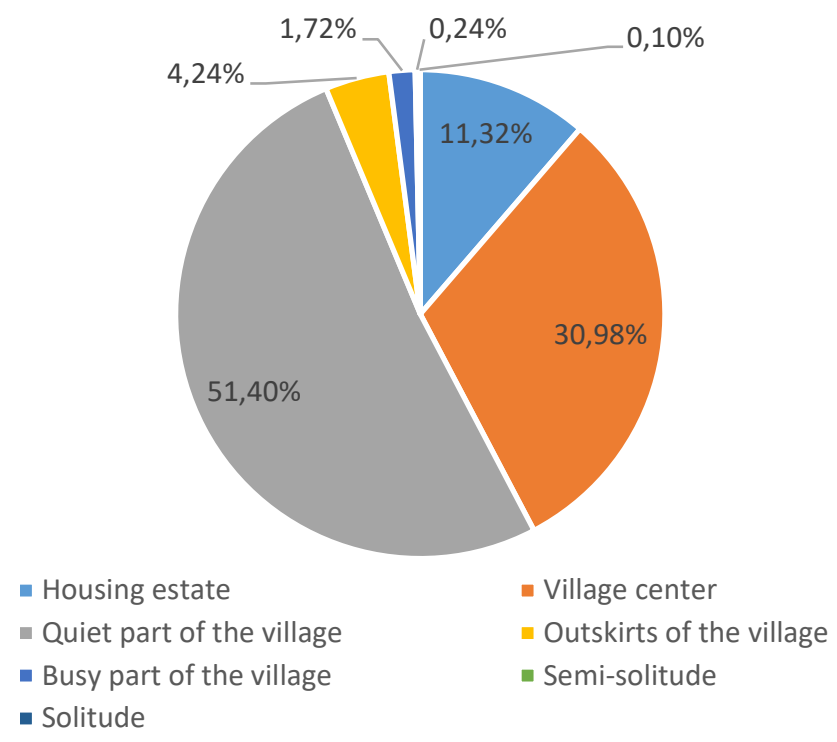

Figure 6: The structure of apartments offered for sale in terms of the location, January 2018 to June 2021 Source: Software EVAL

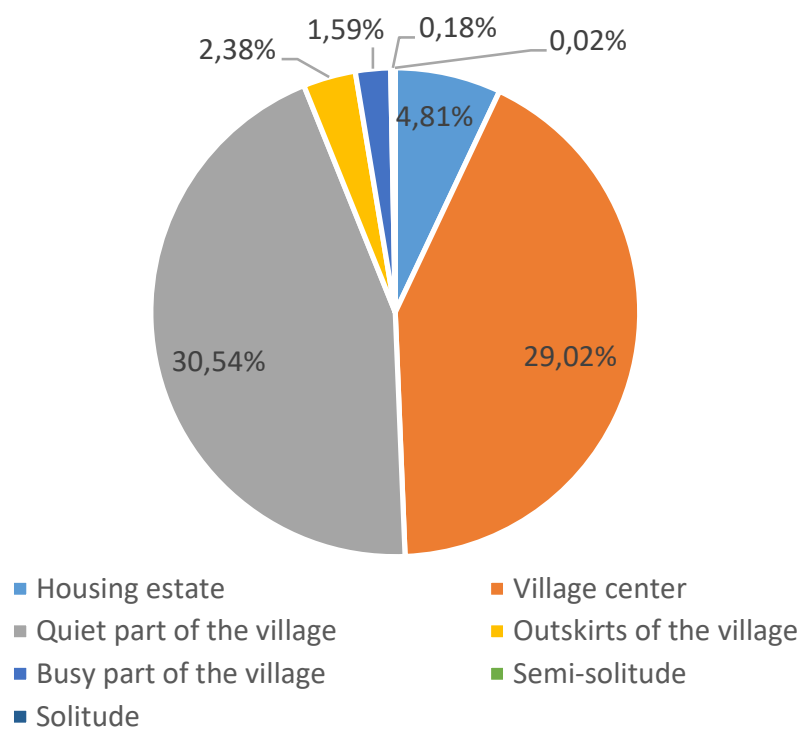

Figure 7: The structure of apartments offered for rent in terms of the location, January 2018 to June 2021 Source: Software EVAL 


\section{References}

[1] Hromada, E. (2019). Real estate prices in the Czech Republic: Behavioral approach. In: Engineering for Rural Development, Proceedings of 18th International Scientific Conference. Jelgava: Latvia University of Agriculture. p. 1795-1800. ISSN 1691-5976.

[2] Hromada, E. (2016). Real estate valuation using data mining software. Paper presented at the Procedia Engineering, pp. 284-291. doi:10.1016/j.proeng.2016.11.621.

[3] Hromada, E. (2015). Mapping of real estate prices using data mining techniques. Paper presented at the Procedia Engineering, pp. 233-240. doi:10.1016/j.proeng.2015.10.083. 